\title{
Educação Científica e Educação Literária
}

\section{Introdução}

A propósito dos 250 anos do nascimento de J. W. Göethe, escrevi neste mesmo Boletim, já lá vão mais de dois anos, algumas consideraçōes em torno do tema «A Química na Cultura e a Cultura na Química», sem intenção de trazer para a luz da ribalta qualquer das acesas discussões que a separação entre a actividade dos "intelectuais literários" e a actividade dos "cientistas da Natureza" tantas vezes tem suscitado. Realçando a acção humanista e científica de J. W. Göethe, numa altura em que a sua figura era evocada de muitas e variadas formas, foi meu simples propósito pugnar pela componente humanizante que a prática científica pode comportar e sem a qual facilmente se pode converter em funesta ameaça e agressão à nossa existência quotidiana ${ }^{1 .}$.

Alguns leitores dessas minhas considerações que por escrito me fizeram chegar os seus comentários, queriam que tivesse ido mais longe e tivesse claramente entrado no debate da cultura que os intelectuais do mundo das Letras têm como apanágio seu confrontada com a cultura que os estudiosos das ciências Exactas e da Natureza, na especialidade de seus domínios científicos, de igual modo para si reclamam.

Considerando o debate público que hoje se trava, em todo o país, em torno do Ensino que temos, contra o qual se erguem por toda a parte as mais ferozes queixas de inadequada organização curricular, deficiente programação e manisfesta ineficácia no seu objectivo de criar cidadãos que ao deixarem o En- sino obrigatório se tenham como minimamente cultos e com uma formação científica minimamente aceitável, julgo ser momento oportuno para aceitar o repto de alguns desses leitores para levantar aqui o problema, seja na sua componente histórica, seja numa perspectiva que poderemos considerar de propedêutica.

\section{2. "Literatura e Ciência"}

O título "Literatura e Ciência» de que me sirvo para rotular este parágrafo é conscientemente plagiado do título da Rede Lecture proferida por Mathew Arnold, em 1882, na Casa do senado da Universidade de Cambridge ${ }^{2}$ Mathew Arnold era, ao tempo, "o mais destacado homem de letras da Inglaterra Vitoriana", a quem os seus pares dos estudos literários consideravam "o principal apóstolo da cultura" ${ }^{\text {"3. }}$.

Em si mesmo, o título em causa é passivel de duas leituras imediatas: 0 dualismo dos estudos literários (= a Literatura) em contraposição com os estudos das leis que regem os fenómenos naturais (= a Ciência); ou a consideração do carácter sistemático e organizado dos estudos literários da lingua e da história na base do qual a Literatura reclama para si o estatuto de "ciência" que os investigadores do mundo natural tendiam a considerar apanágio exclusivo do método por eles utilizado em seus estudos.

Com a Revolução Industrial e, particularmente a partir dos finais do século XVIII e ao longo do século XIX, criou-se um distanciamento profundo entre os estudiosos dos fenómenos do mundo natural, os homens da física, da química e da história natural e os estudiosos do mundo humano, os homens das Artes, das Letras e da Filosofia. Sem prescindir do carácter rigoroso do tratamento matemático, o estudo dos fenómenos naturais caracterizava-se por um tratamento sistemático de indução e dedução considerado portador de novos critérios do que poderia ser tido por verdadeiro conhecimento, deixando completamente de fora todos os aspectos teológicos e metafísicos. 0 estatuto de ciência foi rapidamente apropriado por esse estudo.

Esta apropriação do estatuto de ciência cavou um fosso profundo entre os estudiosos do mundo humano e os investigadores do mundo natural, entre as humanidades e as ciências. Sociologicamente, o carácter nobre que ao longo dos séculos sempre fora reconhecido à Teologia e à Metafísica, foi, a princípio, favorável aos estudiosos do mundo humano. $\mathrm{O}$ estudo das humanidades gozava de mais elevado estatuto que o estudo das ciências. Este foi estigmatizado, durante muito tempo, como "uma actividade profisional não excessivamente limpa, e de modo nenhum conveniente no que respeita à educação de um cavalheiro", em particular, se se tratava das ciências aplicadas ${ }^{4}$. Falho o estatuto de ciência, os estudiosos das humanidades gozavam em regime de quase exclusividade do estatuto de cultura. A educação literária é que era a grande fonte de cultura e a solução educacional de maior prestígio social e maior contributo para o bem estar da Nação. 
O correr do tempo foi, todavia, desfavorável a esta tendência geral. Da crescente institucionalização do ensino das ciências nas instituições universitárias e crescente recrutamento das categorias superiores da administraçẫo pública de entre as fileiras dos homens de ciência, resultaria um salutar equilíbrio entre o estudo das ciências e o estudo das humanidades e entre as instituições que ministram uns e outros e, ainda, entre as classes sociais.

Hoje, os dois grupos de estudiosos, os estudiosos do mundo humano e os estudiosos do mundo natural, reclamam para si, com similar fundamento, o estatuto de cultura e o estatuto de ciência.

Foi neste sentido que M. Arnold desenvolveu a sua Rede Lecture, no longinquo ano de 1882, respondendo às acusaçōes que T. H. Huxley, dois anos antes, na abertura do Mason College de Birmingham, lançara sobre os adeptos da educação clássica tradicional. Defendendo que "a ciência fazia parte da cultura e facultava uma preparação mental rigorosa, ao mesmo tempo que representava um contributo inestimável para o bem-estar da Nação", T. H. Huxley, denunciara a resistência às reivindicações da educação científica pelos adeptos dos programas clássicos tradicionais, considerando-os "simultaneamente arbitrários e de vistas curtas"

Na sua Conferência Literatura e Ciência, M. Arnold defendeu que a literatura e a ciência não podiam ser tratadas nem tidas como dois saberes completamente estranhos um ao outro, considerando que sem qualquer deles, é falha a educação aperfeiçoada dos cidadãos. $\mathrm{Na}$ defesa da sua dama, deixava peremptoriamente claro que "o estudo das ciências naturais pode produzir um especialista cheio de valor prático, mas nunca um homem culto". Para tanto, tinha por absolutamente indispensáveis os estudos literários, especialmente o estudo das literaturas da Antiguidade, concedendo muito embora, que a a categoria da literatura deveria compreender não só os grandes clássicos das Letras, mas todos os grandes clássicos do conhecimento, incluindo expressamente na lista destes os Principia de Newton e A Origem das Espécies de Darwin.

Não foram precisas grandes lutas para que qualquer sistema de ensino dos paises do chamado Mundo Ocidental aceitasse e consagrasse nos seus curricula a necessidade dos estudos literários em conjunto com os estudos das ciências como parte integrante duma educação aperfeiçoada de todo e qualquer cidadão. As assim chamadas "duas culturas", a dos estudos das humanidades e a dos estudos dos fenómenos naturais, a duma educação literária e a duma educação científica ${ }^{6}$, passaram a integrar os planos curriculares dos diversos sistemas de ensino nacionais, num primeiro período de carácter formativo geral, independentemente da sua diversidade. A especialização foi invariavelmente relegada para um período mais tardio, não importa se já fora ou ainda dentro do sistema de ensino obrigatório.

\section{Da necessidade, tempo e modo da especialização}

0 acordo entre os intelectuais literários e os intelectuais da ciência reconhecendo a necessidade de ambas as suas culturas para a educação aperfeiçoada de todos os cidadãos é para cada uma das partes um acordo minimalista. Na sua visão tecnocrática do bem-estar da $\mathrm{Hu}$ manidade, os intelectuais da ciência acreditam facilmente que só a ciência pode resolver os problemas com que 0 desenvolvimento humano se confronta no dia a dia. Por sua vez, os intelectuais literários, pouco à vontade com o avassalador e tantas vezes extremamente perturbador poder da máquina, sentem que este é ameaça fatal ao desenvolvimento do espírito e que só a cultura literária é verdadeiro e único repositório das soluçöes mais fundamentais e humanas, em todos os sentidos da palavra, de toda a Humanidade.

Numa posição de confronto mútuo, os intelectuais da ciência acusam os intelectuais da literatura de dispenderem uma energia excessiva em pormenores bizantinos e serem, por natureza, verdadeiros ludistas ${ }^{7}$. Do outro lado, os inte- lectuais da literatura acusam os intelectuais da ciência de inconscientes e impiedosos subversores dos valores humanos, dominados por interesses extremamente limitados pela utilidade e pela quantidade, esquecidos de que os maiores valores humanos são os de ordem moral.

Se na educação geral de cada indivíduo não for devidamente doseada a especialização que tende a extremar nele uma das "duas culturas" em confronto, o fosso entre os intelectuais da literatura e os intelectuais da ciência tornar-se-á cada vez mais profundo, com graves rupturas recorrentes na história cultural das sociedades em que se dá.

Impõe-se pois, que os mais diversos sistemas educativos em que, nas diferentes sociedades, se formam os cidadãos que engrossam as fileiras de cada uma das culturas em confronto procurem atenuar e reduzir até ao máximo possível a cisâo estrutural da vida do espírito. E porque esta se tece nas malhas da especialização, é no campo desta que se impõe agir quando se pretende obviar ao máximo aos malefícios do fosso que numa sociedade, separa as duas.

No vasto mundo e diversidade dos saberes do nosso tempo, é impensável fazê-lo com um não quase absoluto à especialização. 0 desenvolvimento do saber atingiu um ponto de não-retorno impossivel ao "de omne re scibile" de há uns séculos atrás. Citando uma vez mais S. Collini podemos dizer que "o processo de especialização enquanto tal é, hoje, uma condição preliminar do progresso intelectual, e amiúde, um aperfeiçoamento sensivel das ideias e das técnicas" ${ }^{8}$.

Se não é possivel fugir ao processo de especialização que por si próprio cava o fosso entre as "duas culturas", parece ser evidente que para atenuar os malefícios que dele naturalmente decorrem, a nivel do cidadão e a nível da sociedade, se impõe "regulá-lo" de modo a minimizar os efeitos nocivos e maximizar os efeitos benéficos que em si mesmo a especialização simultaneamente contém. 
Dois factores parecem passiveis de imediata regulamentação: o tempo em que se faz e o modo como se faz.

Referindo-nos ao tempo em que a especialização deve ser feita, não queremos centrar a nossa atenção na duração por que se deva estender. É que uma vez iniciado o processo, ele passa a fazer parte integrante do indíviduo que nele se envolveu. Intervir no seu desenrolar joga, a partir de então, com a liberdade pessoal de acção que nem sempre se compadece facilmente com regras pre-estabelecidas de regulamentaçã̃o. Referimo-nos pois, ao tempo em que ela é imposta como uma vertente do sistema educativo em que o individuo está inserido.

Nos termos da actual Lei de Bases do Sistema Educativo Português, não há especialização na formaçāo escolar dos cidadãos até ao fim do $3 .^{\circ}$ Ciclo do Ensino Básico, que constitui, neste momemto, o termo do ensino obrigatório. Cumprindo os planos curriculares, neste estágio da sua formação académica, a todos os cidadãos portugueses foi ministrado o mesmo repositório de saberes.

A especialização académica dos saberes, em Portugal, impõe-se com o ingresso no Ensino Secundário.

0 aluno com um percurso regular dentro do sistema tem então 14-15 anos. 0 leque de diversificação que neste momento de Ensino já não obrigatório the é oferecido compreende actualmente quatro agrupamentos (cientifico-natural, artes, económico-social e humanidades). Ao escolher qualquer um deles, o aluno está a fazer uma opçầo decisiva que, por norma, vai conformar toda a sua vida. Poderá sempre voltar atrás, mas só o poderá fazer com perdas e custos para sempre irreparáveis.

É muito precoce esta idade em que o aluno tem de fazer esta opção de especialização. Os efeitos culturais da especialização, a nivel da formação secundária, como mais tarde a nivel da formação superior, são motivo de ansiedade e ponderação tais que a formação educativa especializada numa fase excessivamente precoce poderá ser terri- velmente nefasta. $\mathrm{O}$ adiamento da escoIha deste tipo de especialização para um periodo de maior maturidade seria altamente benéfico. Os 17-18 anos seriam uma idade muito mais aconselhável para o efeito.

Outros factores importantes dos próprios requisitos do sistema escolar suportam de igual modo a grande conveniência de se adiar o mais possivel a especialização da formação escolar. Por um lado, está em curso uma rápida massificação do Ensino Secundário e até do Ensino Superior: os jovens são cada vez mais encorajados a participar no ensino e na formação pós-obrigatória, criando-se um clima não já de obrigatoriedade legal de frequência escolar, mas de obrigatoriedade social. Este rápido crescimento da escolarizaçẫo do ensino pós-obrigatório impōe a diminuição da diferenciação no Ensino Secundário. Por sua vez, a evolução da economia de mercado aponta cada vez mais no sentido de profissionais mais polivalentes, fomentando um aumento do leque de competências dos jovens à entrada do mercado de emprego ${ }^{9}$.

A formação geral e a desprofissionalização fazem parte da actual ideologia macroeconómica global e hegemónica do discurso político educacional a nivel internacional, pouco apologista de uma mão-de-obra muito especializada à saida do sistema escolar, sobretudo a nivel do Ensino Secundário ${ }^{10}$.

Alongar a escolaridade geral obrigatória e adiar a idade de escolha entre os vários tipos de formaçōes gerais, técnicas e profissionais, torna-se pois, um desideratum cada vez mais premente.

Por outro lado, é notória e deplorável a incultura científica, histórica e filosófica do cidadão que se ficou pela formação académica geral do ensino obrigatório, a nível do $3 .^{\circ}$ ciclo do Ensino Básico. Mesmo admitindo que essa formação se encontra em patamares de rendimento muito aquém das potencialidades que o sistema comporta se devidamente rentabilizado, são manifestas as falhas de formação geral que Ihe são inerentes e que não se afiguram fáceis de suprir sem uma extensão do tempo de formação.

0 alargamento do ensino obrigatório para além do actual $3{ }^{\circ}$ ciclo do Ensino Básico e o adiamento da especialização do Ensino Secundário para uma fase mais tardia deste, ou mesmo definitivamente relegada por completo para o Ensino Superior, parece ser inevitável. Um e outro são já prática corrente em muitos países do mundo Ocidental, nomeadamente na maioria dos paises europeus, onde é crescente a atracção por uma "formação geral" e marcada a decisão de desespecializar e desprofissionalizar os percursos mais ligados ao ensino não-superior ${ }^{11}$.

Numa altura em que está em curso uma reorganização curricular dos Ensino Básico e Secundário, parece-nos ser altura apropriada reformular o Ensino Secundário que temos, seguindo um padrão já generalizado em muitos dos referidos paises, organizando-o em dois ciclos $\left(10 .^{\circ}-11^{\circ}+12^{\circ}\right.$, ou $\left.10 .^{\circ}-11 .^{\circ}+12^{\circ}-13 .^{\circ}\right)$, em que o plano curricular do primeiro seja exactamente o mesmo para todos os estudantes que o frequentem, e só no segundo se entre em alguma diferenciação entre uma formação geral e uma formaçāo profissional. Até ao fim do primeiro ciclo do Ensino Secundário todos os estudantes deveriam receber a mesma formação geral, uma formação que articulada com a do Ensino Básico se traduza num elevado nível de utilização, no dia a dia, das competências em Matemática, Física, Química, Ciências Naturais, Lingua Pátria, Lingua Estrangeira de Comunicação e Lingua Estrangeira de Cultura que se espera do bom cumprimento de um programa destas disciplinas, sagazmente adequado às necessidades reais do pais, nos respectivos domínios do saber; e se traduza também numa formação básica, suficientemente satisfatória do ponto de vista de cultura geral, em História, Geografia, Filosofia e Sociologia. Deseja-se que todo o cidadão que cumpriu com aproveitamento a etapa do Ensino obrigatório conheça bem os "comos" e os "porquês" dos conteúdos que os programas das referidas cadeiras tiveram como objectivo infundir-Ihe e saiba 
deles usar e dispor com correcção e dextreza, no dia a dia.

Defendido o adiamento da especialização da formação académica para a parte terminal do Ensino Secundário, com um alargamento deste a todos os jovens, proporcionando-lhes uma escoIha de formação especializada numa idade mais madura, e uma formação geral mais vasta para o cidadão em geral, resta-nos dizer alguma coisa sobre o modo como a formação especializada poderá ser regulamentada de maneira a atenuar o fosso que ela mesma cava entre as "duas culturas" de que falámos.

Quanto maior for a especialização, comece ela no Ensino Secundário ou ocorra apenas a nivel do Ensino Superior e posterior actividade profissional, mais rigidas serão as separaçōes entre as disciplinas que formam o tecido cultural de cada um dos lados do fosso; mais acentuadas serăo as linhas divisórias; mais intensos serão os sentimentos de superioridade ou desprezo entre os grupos profissionais formados, porque mais profunda será a diferença entre ambos.

A profundidade da separação decorrente duma especialização intensa poder-se-á atenuar alargando o leque da especialização. Sem afectar a profundidade da especializaçāo, da sua diversificação resultarão necessariamente múltiplos grupos culturais entre os quais a radicalização se torna mais difícil, até ao ponto de se poder ser levado à situaçāo caricata de alguns deles se poderem interrogar com toda a legitimidade sobre de que lado devam ser considerados, na divisão dicotómica do campo cultural: do lado dos intelectuais da literatura ou do lado dos intelectuais da ciência? Na especialização muito diversificada, o fosso entre as "duas culturas" perde a sua alteridade porque mais do que "duas culturas", passarão a existir um sem número delas, cada qual com a sua linguagem própria e os seus próprios pontos de referência. A separação cultural entre os diferentes grupos profissionais que dai resulta continua, mas esvai-se a diferença de poder entre eles, pelo simples facto de a multiplicidade implicar fragmentização.
Tentar atacar deste modo o perigo decorrente da existência do fosso cavado entre as "duas culturas" será optar pelo clássico "dividir para vencer". Não nos parece que este seja o melhor "modo" de regulamentação da especialização cultural. Á aproximação das "duas culturas" por um processo de divisão, em que as diferenças entre ambas se diluem pelos muitos compartimentos criados, preferimos uma aproximação concretizada num espaço cultural duma intersecção comum a ambas.

Não se trata de tentar substituir as "duas culturas" em confronto por aquilo que já foi chamado a "terceira cultura" de que os historiadores da sociedade muitas vezes se arrogam serem os mais legitimos representantes. Porque a ciência só por si não fornece todas as luzes necessárias para o governo do mundo e porque as humanidades têm muito a rever para se adaptarem às necessidades de uma sociedade dominada pela ciência e pela tecnologia, imperioso se torna que na definição da ordem das disciplinas que levam à cultura caracterísitica do dominio de cada uma das duas culturas em confronto se preste atenção mais às semelhanças do que às diferenças entre as operaçōes mentais de um lado e de outro da fronteira que separa a ciência das humanidades. Essa atenção pressupõe que no periodo de especialização mais especifico e mais determinante, o período em que se cumpre o plano curricular do Ensino Superior, se deixe ben claro que as diferentes formas de inquirição intelectual, que fornecem adequadamente diferentes formas de conhecimento ou inteligibilidade, não constituam, nenhuma delas, de per si, um modelo a que as demais se devam conformar.

0 trabalho dos historiadores, filósofos e sociólogos da ciência tem aqui insubstituivel funçāo. Tornada uma componente forte da formação especializada dos homens da ciência e dos homens da literatura, com as necessárias adaptações necessárias à mais adequada apresentação de matéria idêntica a discentes com interesses e conteúdos de formação diferentes, a história social da ciência, na sua análise dos factores sócio-culturais que impelem a investigação em ceratas direç̧ões preferenciais e as necessidades sociais e psicológicas subjacentes aos ideais do profissionalismo e do desinteresse, mostrará a uns e outros, os intelectuais da literatura e os intelectuais da ciência, que a cultura de cada um deles é apenas uma expressão do modo como a sociedade se orienta em relação ao mundo, ambas elas inseparáveis das questões fundamentais da ordem política e moral sobre que a mesma assenta ${ }^{12}$.

A História, Filosofia e Sociologia das Ciências, nesta visão, é hoje, uma componente forte da formação académica, consagrada nos respectivos curriculos disciplinares, oferecida pelas mais prestigiadas Intituiçōes de Ensino Superior. O seu enraizamento em algumas delas conta já com várias décadas de existência e está bem patente na própria estrutura em que a Instituiçāo se organiza. Sublinhando o carácter de interdisciplinaridade entre a cultura dos homens da ciência e a cultura dos homens da literatura, em muitas dessas Instituições essa formação é ministrada em Unidades de Ensino e Investigação próprias, com autonomia idêntica à de qualquer outra Faculdade ou Departamento, com iguais exigências de formação específica do seu corpo docente/investigador, cientificamente creditado na interdisciplinariedade requerida, que o amadorismo é, em principio, fonte de descrédito.

É o caso, por exemplo, da formação académica oferecida pelo Massachussets Institute of Technology (MIT), em Cambridge dos USA, ou pelo California Institute of Technology (CALTECH), em S. Francisco do mesmo país, duas das mais prestigiadas instituições de formação científica, em todo o mundo. Tratando-se de duas Instituições criadas de raiz para promover a formação académica de cariz tecnológico, como o próprio nome indica, ambas elas tomaram para base da sua organização duas unidades básicas: por um lado, as Escolas (no caso do MIT) ou Divisōes (no caso do (ALTECH) de formação no domínio dos estudos dos fenómenos naturais (a Biologia, a Física, a Matemática, a Astronomia, a Química, as Engenharias); e 
por outro lado, a Escola ou Divisão das Ciências Sociais e Humanas. A estrutura de ambos estes Institutos está toda consignada na base destas duas unidades de formação académica em que o número de créditos exigidos como obrigatórios da formção específica de cada uma delas para titular o grau que confere deixa lugar para um elevado número de créditos de livre escolha por parte dos formandos ${ }^{13}$.

O simples título de alguns tópicos das diferentes áreas de investigação dominantes na Escola/Divisão das Ciências Sociais e Humanas de qualquer dos dois Institutos de Tecnologia são só por si significativos relativamente ao objectivo perseguido: História moderna das Ciências Físicas; História da Física e Filosofia das Ciências Físicas; Filosofia da Ciência, Filosofia da Biologia, Filosofia da Linguística; Ciências Naturais e Literatura; Filosofia da Psicologia e da Linguistica; Ciência, Ética e Sociedade...

A pouco e pouco, com bastante atraso, com evidentes avanços e recuos e danos irreparáveis pelo meio, também em Portugal há Instituições de formação académica apostadas no desafio de aproximação das "duas culturas". A aposta passa pelo debate em torno do tempo e do modo da especialização cultural que referimos

Para que ao tempo próprio da mais eficaz especialização, o tempo do Ensino Superior, os que se movem nos domínios específicos da cultura literária se possam sentar lado a lado com os que se movem nos domínios da cultura da ciência importa que uns e outros tenham sido expostos a um comum conjunto equilibrado de matérias até tão tarde quanto possivel.

\section{Referências}

${ }^{1}$ A. M.Amorim da Costa, Química, 75 (1999), 26-29.

${ }^{2} \mathrm{M}$. Arnold, Literature and Science in The Complete Works of Mathew Arnold, (R.H. Super, Ann Arbor, 1974) vol. X, pp.52-73.

${ }^{3} \mathrm{~S}$. Collini in C.P. Snow, As duas Culturas, (Ed. Presença, Lisboa, 1996) Introdução, pp.15-16.

${ }^{4}$ Idem, p. 14.

${ }^{5}$ T. H. Huxley, Science and Culture (1880) retomado em T. H. Huxley, Science and Education: Essays, Londres, 1893, 134-159.

${ }^{6}$ cf. em particular, C. P. Snow, The Two Cultures in New Statesman, 6.Out.1956; Idem, The Two Cultures and the Scientific Revolu- tion, Rede Lecture, Cambridge 1959, trad As Duas Culturas, (Publ. D. Quixote, Lisboa, 1965, col. Vector, n. ${ }^{\circ} 1$ ); Idem, Ed. Presença, Lisboa, 1993.

${ }^{7}$ Nota: Ludismo: movimento anti-máquina, surgido no Norte de Inglaterra, nos principios do século XIX, liderado pelo mítico Ned Ludd que terá guiado os artesãos do Lancashire no incêndio generalizado das fábricas da região.

${ }^{8}$ S. Collini, loc. cit., p. 50).

${ }^{9}$ Joaquim Azevedo, O Ensino Secundário na Europa:o neoprofissionalismo e o sistema educativo mundial (Universidade do Porto, Tese de Doutoramento, 1998), pp. 324-325.

10 Idem, p. 561

11 Idem, passim

12 J.Golinski, The Theory of Practice and The Practice of Theory - Sociological Approaches in the History of Science in Isis, 81 (1990), 492-505.

${ }^{13}$ A organização e demais informação sobre as referidas Instituições pode ser consultada nas páginas da Internet: http://www.hss.caltech.edu e http:// www. mit.edu.

\section{he yides}

Equipamento de Laboratório

Balanças - Centrifugas - Aparelhos de $\mathrm{pH}$ - Tituladores Condutímetros - Agitadores - Espectrofotómetros Microscópios - etc.

Vidros e Plásticos de Laboratório Distribuidores NORMAX

Material Didáctico

Ensino Secundário e Superior

Representantes exclusivos SISTEDUC - Sistemas Educativos S.A.

Rua Soeiro Pereira Gomes, 15 r/c Frente Bom Sucesso - 2615 Alverca

Telefs. (01) 95704 20/1/2 - Fax (351-1-957 04 23) - Portugal 